\title{
CONSTRUYENDO UN MUNDO A TRAVES DE LA LITERATURA PARA NIÑOS
}

\author{
Magdalena Vásquez Vargas
}

\begin{abstract}
Adela Ferreto is given her place in the development of Costa Rican literature for children. Besides, her main writings for children are analyzed in order to reveal the writer's ideological proyect and the main rhetorical device she uses to communicate with children.
\end{abstract}

\section{Introducción}

Los críticos costarricenses han visto en forma marginal la literatura infantil. Abelardo Bonilla y Virginia Sandoval apenas hacen una reseña general de los autores más significativos de la primera mitad del siglo veinte. Margarita Dobles, quien escribe en 1981 el libro Literatura infantil para la Universidad Estatal a Distancia, dedica tambićn escasas páginas al estudio de la literatura para niños producida en nuestro país.

Es difícil ubicar a Adela Ferreto en un grupo determinado, debido a que sus escritos pertenecen a distintos momentos históricos. En 1922 publica en la Revista Ardua una obra de teatro infantil llamada "Tía Tortuga ayuda a Tío Conejo". En este texto se muestra como fiel seguidora de su maestra María Isabel Carvajal - Carmen Lyra-. Esta influencia se percibe también en dos de sus cuentos publicados a partir de 1982, El príncipe viejito y Las aventuras de tío conejo y Juan Valiente, en donde la utilización del lenguaje campesino costarricense es similar al empleado por Carmen Lyra en Los cuentos de mi tía Panchita, y en los que se retoman algunos de los personajes de este libro como: Tío Conejo y Uvieta.

En 1982, junto a Marilyn Echeverría, Delfina Collado, Floria Jiménez y Luis Bolaños publica en una antología llamada País de magia. A partir de este año son siete los libros de literatura infantil que edita Adcla Ferreto: Las aventuras de Tío Conejo y Juan Valiente (1982), El príncipe viejito (1983), La novela de los viajes y aventuras de Chico Paquito y sus duendes (Premio Aquileo J. Echeverría, 1983), Tolo el gigante viento norte (Premio Carmen Lyra, 1984), Las palabras perdidas y otros cuentos (1986) y dos libros postumos: Cuentos del Niño Dios y de la tradición cristiana (1992) y Cuentos y leyendas de animales (1992).

María Pérez Yglesias resuelve el problema generacional de Adela Ferreto ubicándola como una autora de transición, que representa los rasgos más característicos de la primera época de la literatura infantil y es pionera de las nuevas tendencias de ésta (Pérez, M., 1991: pág. 16).

De este primer momento hereda rasgos que luego van a ser característicos de sus producciones posteriores, como la necesidad de rescatar el folclore costarricense y su preocupación por lo didáctico. Estos, a su vez, coexisten con otros aspectos como el aprovechamiento de la tradición oral de los pueblos indígenas y la denuncia de la problemática ecológica, que según María Pérez Yglesias la evidencian como precursora de las nuevas tendencias de la literatura infantil costarricense.

En el estudio realizado por Adela Ferreto sobre la literatura infantil costarricense, ella destaca la labor de Joaquín García Monge, Carlos Luis Sáenz y Carmen Lyra, y se autodefine como seguidora de Carmen Lyra. De ella hereda fundamentalmente su interés por el folclore y por el lenguaje popular.

La trascendencia de Adela Ferreto en la literatura infantil costarricense la recoge María Pérez Yglesias en su estudio "La literatura infantil en 
Costa Rica y el mundo mágico de Adela Ferreto", uno de los trabajos más serios, sistemáticos y actualizados que se han escrito en este campo. A continuación se resumen las razones que llevan a María Pérez (1984:101-102) a afirmar que Adela Ferreto es una de las figuras más sobresalientes de la literatura infantil costarricense:

a. Sustituye a Carmen Lyra como profesora de la Escuela Normal de Heredia

b. Traduce y adapta textos para la infancia y la adolescencia

c. Realiza ensayos teóricos sobre la literatura infantil

d. Elabora con Carlos Luis Sáenz y Luisa González la revista infantil Triquitraque (19361948)

e. Es miembro fundador del Instituto de Literatura Infantil y Juvenil del Ministerio de Cultura, Juventud y Deportes (1984)

f. Posee una vasta producción de literatura infantil. Tiene varios textos publicados y otros inéditos.

g. Es ganadora de dos premios nacionales.

María Pérez concluye en su artículo diciendo que existen tres dicotomías fundamentales en la producción de Adela Ferreto: la del pasado que nutre al presente, la de la realidad que pasa a la fantasía y la de lo universal que dialoga con lo nuestro. Asimismo destaca la preocupación de Adela por lo autóctono, los valores humanos y la contaminación de que ha sido objeto la naturaleza.

Como se ha hecho referencia, Adela no sólo escribe para niños sino que teoriza sobre el fenómeno literario. Sobre éste se detiene en dos aspectos fundamentales: el oficio del escritor y las fuentes de la literatura infantil.

\section{El oficio del escritor}

En el ensayo escrito por Adela Ferreto "El oficio del escritor", ella define al escritor en primer instancia como un trabajador más de la sociedad que tiene que prepararse para realizar con eficacia su labor: leer, conocer la lengua popular y culta, la literatura de otros pueblos y culturas. Además, el escritor debe saber sobre el hombre, la historia y las sociedades:

\footnotetext{
"Hay que conocer al hombre en su ser actual y en su devenir a través de las edades y hacia el futuro, a lo largo y a lo ancho de la Tierra; hay que tratar de penetrar su misterio, su
}

animalidad y su humanidad, su tragedia, su gloria y su miseria" (Ferreto, A. "El oficio del escritor". Sin fecha. Pág. 1).

Al definir el oficio del escritor define parte de su experiencia; para ella toda su producción surge del conocimiento que ha adquirido de hombres y culturas. Entre más vasto es el conocimiento del mundo a través de los libros y de la observación cotidiana, mayor será el diálogo de sus textos literarios con el texto general de la historia y la cultura.

También considera que el escritor debe ser un individuo capaz de denunciar abiertamente los errores de la humanidad y de promover a través de los textos las transformaciones que la sociedad necesita.

Además de lo anterior, el escritor reúne otras características: es guía, profeta y mago. Para explicarlas hay que comprender a Adela como sujeto de la escritura. Su definición de escritor como guía está implícitamente determinada por su rol de maestra; la de profeta alude al Martí, visionario que admira y de quien hereda su preocupación por lo venidero; y la concepción de mago se orienta a que el escritor debe aprehender lo mágico y misterioso que tiene el mundo y expresarlo por medio de un sabio juego de palabras.

La definición que presenta inicialmente Adela en un tono objetivo y científico, en la que el escritor es un trabajador capaz de producir a partir del conocimiento del mundo y de la observación de los materiales que le ofrece el contexto histórico, se subjetiviza cuando partiendo de sus propias concepciones, experiencias e inclinaciones, lo describe como guía, profeta y mago.

\section{Fuentes de la literatura infantil}

Al ocuparse de las fuentes, particulariza en la literatura infantil. Según su estudio Las fuentes de la literatura infantil y el mundo mágico, las fuentes son tres: el folclore, los textos clásicos de los que por su belleza, el niño se apropia, sin ser escritos necesariamente para él, y los elaborados pensando en el niño como destinatario.

El folclore es para ella el más importante, pues en éste coexisten el juego, el misterio y la magia. Las leyendas, rondas y cuentos de los que ella se apropia en su niñez son parte de este folclore, cuyo origen se extiende a la humanidad. Muchos de los seres mágicos que pueblan las narraciones populares, violan todas las fronteras; 
duendes y aparecidos, bajo diferentes formas y vestuario, y con un lenguaje peculiar, participan en la literatura oral de los distintos pueblos.

El folclore, expresado primero en la oralidad, pasa luego a los textos de escritores que llegan a ser representativos en la historia de la literatura universal.

"Pademos decir que los clásicos, y la gran mayoría de las obras de grandes escritores, accesibles a los niños, tuvieron sus raices en el folclore, especialmente, en el mundo feérico y fantástico, por lo que tienen el encanto de los cuentos de hadas." (Ferreto, A, 1984a: pág. 7).

Del alma del pueblo, según sus palabras, surgen la magia, las emociones y los sentimientos. A través de ella se unifica el hombre con el cosmos, en un tiempo eterno donde el pasado, el presente y el futuro son uno y todo es animado: hombres, piedras, árboles...

"Esta alma es nuestro lazo con todo lo viviente, con todo lo existente y por serlo vive en el mundo mágico en el que no hay divisiones...

Esto, sin que a nosotros nos parezca extraño porque ¿no sucede así en los sueños y en las ensoñaciones, cuando habla y se manifiesta nuestro subconsciente cuando nos sumergimos en el mundo mágico, o por el contrario, emergemos de él? (Ferreto, A, 1984a: pág. 30).

La literatura ha sido enriquecida por la mitología creada por los pueblos primitivos, quienes para explicar los fenómenos naturales, utilizan la imaginación e inventan dioses con poderes especiales y capaces de transformarse en animales, plantas o ríos y hasta seres ambiguos con partes del reino animal o vegetal.

En sus escritos, Adela Ferreto recurre a distintas mitologías. Seres del mundo mágico universal habitan sus narraciones. En Tolo el Gigante Viento Norte, el personaje principal es un cíclope, heredado de la tradición griega; en Los viajes y aventuras de Chico Paquito y sus duendes, participan las hadas, los duendes, los silvanos, las ninfas, los silfos y muchos más que pertenecen a la mentalidad mágica de los pueblos nórdicos de Europa: Escandinavia, Finlandia y Laponia. Además, recupera la mitología de Los Aztecas. En Tolo el gigante Viento Norte se narra el mito de la creación según este grupo indígena y la importancia que para ellos tuvo el dios Quetzalcoatl, como dador de la vida y maestro de la artesanía y la agricultura. Sobre los indígenas costarricenses en La creación de la tierra y otras historias del buen Sibú y los bribris, se cuenta el origen de los hombres y de las mariposas.

En este estudio (Las fuentes de la literatura infantil y el mundo mágico) hecho por Adela Ferreto, se reconocen dos fuentes fundamentales: el folclore y los otros textos literarios. Si se entiende el texto literario como espacio intertextual donde, según Julia Kristeva (1974:15), se cruzan y neutralizan múltiples enunciados provenientes de otros textos, la propuesta de la escritora sería incompleta porque ignoraría otros materiales que el escritor utiliza en la producción de sus trabajos.

En una entrevista realizada por Jorge Chen, en 1984, ella amplía esta concepción sobre los elementos que intervienen en el proceso de escritura, definiendo la imaginación creadora como:

"... aquella que sabe mezclar de una manera armoniosa y novedosa, los elementos que existen y que parten de un conocimiento y observación. Todo lo que inventas está basado en lo que ya conoces, pero lo puedes expresar y enfocar de otra manera, buscándole un nuevo ordenamiento a los elementos" (Ferreto, A. citada por Pérez, M., 1984: pág. 113).

Los trabajos escritos por Adela Ferreto son muestra de esa intertextualidad. En ellos dialogan fundamentalmente los textos mágicos, históricos, ecológicos, tecnológicos y religiosos. Todos ellos constituyen una red de sentidos que remiten al Texto General de la Historia y la Cultura; en este caso particular la sociedad costarricense, pero no una sociedad estática, sino una Costa Rica edificándose en interacción con el mundo.

\section{Los duendes: maestros mágicos}

La función que cumplen los seres mágicos en los escritos de Adela Ferreto es esencialmente didáctica.

Duendes y hadas aleccionan a los niños sobre la forma en que deben proteger a la madre naturaleza. El discurso ecológico es emitido en muchos casos por ellos, quienes hasta llegan a presentarse como "maestros en miniatura", como sabios conocedores de la naturaleza. Los duendes Gogo y Trilín participan en el cuento "La oruga y la mariposa", y en éste discuten sobre el proceso de la metamorfosis:

"- No podría tirarlos (los huevitos) sin darse cuenta.

Sabes, es peligroso moverlos mucho, y más, despegarlos de la hoja. Pronto nacerán las larvas, ya te lo dije.

- ¿Los gusanitos peludos? 
- Serán peludos, pero no son gusanos... ¿y qué son?

- Larvas... animalitos en formación ...

- Son gusanos formados, los he visto mil veces: comen, caminan y duermen; también tienen ojos.

¡Gogo de mi alma!, deberías fijarte un poco más, siempre andas pajareando, nunca pones atención... por eso no aprendes. -Sé lo que sabe toda la gente, y sí me fijo.

Lo que pasa es que eso de la meta... meta, ...bueno, como se llame; me interesa, cierto, pero no me gustan esas palabritas tan rebuscadas, tan de domingo que solo sirven para enredar." (Ferreto, A., 1986b: págs. 27-28).

Tras el duende Tin Trilín la escritora -maestra- da su lección de ciencias. El camuflaje de duende se desvanece por momentos ante el lector, y la maestra experimentada con su paciencia y sabiduría se muestra como un espejismo.

En Los viajes y aventuras de Chico Paquito y sus duendes, aparecen también los duendes Gogo y Tin Trilín. Estos seres minúsculos acompañan a Chico Paquito en todos sus viajes. Gogo con sus torpezas se encarga de divertirlo y Tin Trilín es quien le sirve de guía y de profesor; sabe de historia y ciencias. Y con sus poderes lo lleva a presenciar momentos importantes de la historia costarricense como la batalla de Rivas, y además le enseña el valor biológico de los arrecifes.

"Vengan, llamó Trilín, ya vamos a llegar

- ¿ A llegar a dónde? preguntó Chico Paquito

- Al Santuario

- ¿Cuál Santuario?, no veo ninguna iglesia por aquí

- Y quién te ha dicho que todos los santuarios son iglesias? No, Paquito, los santuarios son lugares de recogimiento, de recuerdo. Vamos a visitar el santuario que guarda la memoria de un hecho heroico en el que muchos hombres murieron para que Costa Rica siguiera siendo un país libre.

- ¡Ah sí! Yo me acuerdo de Juan Santamaría...

Mira, Trilín, no me vengas a echar un discurso" (Ferreto, A. 1983: pág. 71).

La función didáctica que cumple el duende Tin Trilín no lo despoja de su magia, más bien lo transforma en el maestro-mago. Cuando Chico Paquito se dirige a Orosí, él se le acomoda en la oreja y lo invita a viajar en alfombra de musgo; con sus poderes mágicos le enseña geografía e historia. El propósito con el que Adela Ferreto escribe este libro, galardonado con el Premio Aquileo J. Echeverría en 1983, es el de rescatar el patrimonio nacional:

"Pensé en Costa Rica, tan linda en casi toda su historia, en su geografía, en su paisaje, y quise que mi nieto, que los niños disfrutaran conociéndola. Disfrutaran de bosques (de lo que queda de ellos), de sus volcanes: subieran a sus altas cumbres, viajaran por los mares, jugaran en sus playas. Quise también que viajaran por su pasado, contándoles algunas páginas de nuestra historia, como se cuenta un cuento de maravilla, sin fechas y casi sin nombres (Ferreto, A, 1984b: pág. 25).

En los escritos de Adela Ferreto, los habitantes de este mundo creado por la mente primitiva, también enseñan valores humanos.

Se presenta un sistema de vida pacífico, solidario y en el que no existe preocupación por los bienes materiales, pues la naturaleza les provee de un habitat perfecto y por eso la protegen. Juegan, ríen y trabajan en armonía; es un mundo en donde no faltan los pequeños traviesos y las reinas, pero estas últimas no son tiranas, sino amorosas con sus súbditos.

"Todos los duendecillos inclinan las cabecitas. Ahora las levantan y echan gorritos al aire. Vuelven a inclinarse y, otra vez, agitan sus gorritos: ¡Viva la Reina!... ¡Viva!...

La Reina les tira besos; puñados de pétalos olorosos que bailan en el viento." (Ferreto, A.,1983: pág. 10).

\section{Personajes rumbo a la perfección}

La preocupación por la influencia que ejerce la literatura sobre el niño, lleva a que en sus escritos Adela Ferreto preferencie fundamentalmente los valores positivos; en éstos los personajes sufren procesos de mejoramiento, se encaminan a la perfección. La Tía Mechuda, como se denomina a la bruja que aparece en Las aventuras de Tío Conejo y Juan Valiente, al final del cuento sale de su encantamiento y se transforma en una hermosa y noble mujer.

A diferencia de la novelística actual en la que los personajes son signos, individuos en los que se debaten fuerzas opuestas, en los que puede coexistir el odio y el amor, la verdad y la mentira, en los cuentos y novelas de esta escritora, los personajes son en su mayoría símbolos, seres de una sola dimensión. Al referirse a los héroes de los cuentos infantiles los describe como aquellos:

"... que cultivan a los niños porque son perfectos. Perfectos en su apariencia, porque son bellos, en su fuerza y valor, enteros en sus virtudes, generosos, leales, desinteresados (el niño no entiende mucho de ambigüedad, es rotundo en sus apreciaciones: sus héroes son de una sola pieza, buenos o malos, feos o bellos, tontos o inteligentes, cobardes o valerosos." (Ferreto, A., 1984a: pág. 28).

¿Hasta dónde la idealización del mundo expuesta por la escritora como necesaria para inculcar valores humanistas es realmente beneficiosa 
para el niño? ¿Permitirá ésta que él adquiera las armas necesarias para enfrentar su vida social? El niño en su transcurrir diario convive con personas imperfectas, con errores y cualidades, y necesita estar preparado para comprenderlos. La literatura debe ayudarle a ello.

Su preocupación humanista no da cabida en la mayoría de sus escritos a aspectos negativos como maldad, mentira, odio e injusticia. Por eso el mundo mostrado en ellos no es el mundo maniqueo de lo bueno contra lo malo, o la belleza opuesta a la fealdad, sino el mundo de lo positivo.

Personajes hermosamente logrados en sus libros, como "El Príncipe viejito" y "Tolo el Gigante Viento Norte", combinan la fealdad física, con la belleza interior. En el caso de Tolo, su imagen imperfecta de cíclope muestra una ternura que cautiva a los niños y los lleva a comprender que tras una fealdad aparente pueden encontrarse valores nobles. En él, el tamaño y la fuerza, se complementan con el miedo y la dulzura. Es un ser mítico hermosamente humanizado por la escritora:

"¡Aquí es!...-¡jTolo, mi Gigante!, exclamó Nisquito,

¡es él, Pedrín, es mi amigo!

Tolo dormía en el mismo centro de la gran copa, en donde el ramaje se abría en rueda formando un verdadero nudo. Dormía en almohada de nube, envuelto en sábanas de nube. Poco a poco, fue levantando la cabezota cubierta de cabellos hirsutos, enmarañados: abrió el ojo enorme como un plato y miró a los niños. La sonrisa no le cupo en la cara, todo él relumbró de alegría.

-Es muy feo, pensó Pedrín, pero simpático...

Nisquito reía y lloraba...

¡Mis niños! Nisquito y Pedrín... ¡Llegaron!

¡No puedo creerlo! ¡Llegaron!”.(Ferreto, A. 1984c: pág. 96).

\section{El proyecto de vida}

En los Cuentos de mi Tía Panchita de Carmen Lyra se presenta un mundo dividido en clases sociales: pobres y ricos. Esta división se remedia en los personajes principales a través del recuerdo mágico. En "Salir con un domingo siete", el compadre pobre llega a superar al rico en recursos materiales gracias al favor de las brujas del bosque; en "Juan el de la carguita de leña", la varita mágica que le da la Virgen María a Juan le permite conseguir todas las riquezas deseadas y con ellas, el amor de la princesa. Ocurre lo mismo en los cuentos "El tonto de las adivinanzas", "El cotonudo", " Escomponte Perinola". En éstos, los personajes principales superan un mundo de miseria a través de la magia y la suerte, y pasan a ser ricos, situación que no anula la división de clases sino la mantiene porque superan su situación económica familiar o individual, pero no la del pueblo.

En las novelas y cuentos infantiles de Adela Ferreto no existe una jerarquía social marcada en los personajes del mundo narrado. No hay ricos ni miserables; los participantes (niños, adultos, ancianos) podrían ubicarse más bien en una clase media. Poseen los recursos suficientes para estudiar, alimentarse, viajar y mantenerse sanos. Miguel, un niño que participa en el cuento "El niño forastero", es de todos ellos el que por su condición de huérfano posee una situación económica más restringida, pero el amor y protección de su abuela lo hacen sentirse verdaderamente feliz:

\begin{abstract}
"Miguel vivía con la abuela Lucha, buena y linda, sobre todo por dentro; risueña, limpia, dadivosa y la mar de trabajadora. El niño había quedado huérfano de padre y madre desde muy tiemo, pero con la abuela, la verdad, no había pasado trabajos; nunca le faltó su bocadito, ni su cama tibia, ni su ropa limpia, ni cantos, ni cuentos, ni amor..." (Ferreto, A. 1991: pág.13).
\end{abstract}

En este cuento se da una exaltación del trabajo, como necesario en una vida sana y útil. Los animalitos mágicos que participan en Las aventuras de Tío Conejo y Juan Valiente son ejemplo de trabajo: colaboran con Juan Valiente y Tío Conejo en el cuidado de su pedacito de tierra y le ayudan al joven Juan a vencer sus pruebas para conquistar a Lih, la princesa del Yurro.

"Gallina Mágica era muy trabajadora: lavaba el maíz y lo cocía para hacer tortillas o tostaba para que reventara en palomitas que a tío conejo y a ella les encantaban. Además siempre estaba al cuidado de avisarle a su amo de los peligros del monte." (Ferreto, A.,1982: pág. 19).

La caracterización que se da de Tío Conejo, personaje popular que tiene su origen en la tradición africana, es la de un campesino trabajador e inteligente; en este caso la astucia no le sirve como en los Cuentos de mi Tía Panchita, para burlarse de sus semejantes, sino para descubrir el misterio de la princesa del yurro. La preocupación de Adela Ferreto por los valores éticos la llevan a transformarlo:

"El conejo es un personaje muy importante en la tradición costarricense; es el personaje importante en los cuentos de mi Tía Panchita, pero este conejo de mi obra nada tiene que ver con el Tío Conejo de Carmen Lyra. El Tío Conejo de Carmen es 
un conejo popular, lleno de mañas y artimañas, muy poco honorable, muy simpático sí, pero también muy sinvergüenza. Ahora bien, el Tío Conejo de mi obra personifica a un campesino honrado. Trabajador y amigo de ayudar, es thasta donde pude- mucho más inteligente y malicioso que Juan Valiente; tal vez en esto sí se parezca al Tío Conejo de los cuentos de Carmen".(Muñoz, F., 1983: pág. 16).

El ideal político de Adela Ferreto es lograr un mundo de justicia social, donde todos tengan los mismos derechos y deberes; este ideal queda resuelto satisfactoriamente en el mundo presentado en los cuentos y novelas infantiles. En cuanto a su preocupación por el desequilibrio del ecosiste$\mathrm{ma}$, éste aparece expuesto en su narrativa desde dos variantes:

1. El hombre por su descuido, violencia y ambición desmedida conduce a la destrucción de la naturaleza, situación que se resuelve en algunos casos mediante el recurso religioso y en otros no se soluciona.

2. El hombre logra la armonía con la naturaleza, la cual resulta necesaria para su sobrevivencia.

En El príncipe viejito y El cuento el Río, río, la destrucción de la naturaleza realizada por el hombre lleva al exterminio del agua y con ella al peligro de la desaparición del género humano; en ambos casos es gracias al poder divino que se resuelven los problemas. Esta solución encuentra su raigambre en la cultura popular de los pueblos cristianos que hallan en Dios la solución a todas sus dificultades.

En El cuento del Río, río es la Virgen María la que deja de mecer a su niño y acude en ayuda de los animales; para ello busca a Isidro Labrador a quien en el cuento se le elimina el calificativo de Santo. Isidro le da unas semillas mágicas, que ella siembra, acabando con la deforestación y devolviendo la vida y alegría al río, las plantas y los animales.

El elemento religioso se encuentra en este cuento al servicio de la conservación de los recursos naturales. El discurso que aparece sobre la Virgen es el de una mujer cercana a Dios y a los hombres. No se le atribuyen poderes mágicos como en otros cuentos de la literatura infantil costarricense, por ejemplo en los cuentos "La negra y la rubia" y "Juan el de la carguita de leña" de Carmen Lyra (En "Juan el de la carguita de leña" la Virgen le otorga a Juan una varita mágica que le permite alcanzar todos sus deseos. En "La negra y la rubia" la Virgen se le aparece a la Rubia en forma de muñequita y en tres ocasiones le concede un vestido, unos zapatos y un sombrero elegantes para que asista a misa y conquiste al príncipe). El narrador siente, en este cuento, un profundo respeto por la Virgen y la pone a dialogar con los seres de la naturaleza. Ella corre por el río que es un lecho de arena y piedras y se encarga de sembrar las semillas que volverán la naturaleza a su ritmo habitual.

Adela le permite a la naturaleza manifestarse, criticar, sugerir; escucha su voz, durante tanto tiempo ignorada por el hombre y le da un lugar primordial en sus escritos. Para lograr su propósito de sensibilizar al lector, la transforma en personaje dándole un lenguaje humano, no porque el sonido del viento, el pájaro o el bosque dejen de ser hermosos, sino porque la mayoría de los hombres no son capaces de entenderlos. Por eso cuando Toro Torito, le pregunta a Río, río por qué está seco, él le responde:

"-Allá arriba, en el monte, la lluvia no cayó, se secó el ojito de agua que siempre me alimentó; es por eso que mi caudal se agotó".(Ferreto, A.,1986b: pág. 41).

Su discurso aborda al hombre en relación con la naturaleza y describe a esta última como maravillosa y jamás igualable por el hombre.

En Las aventuras de Tío Conejo y Juan Valiente se logra la armonía deseada entre hombre y naturaleza; se muestra la cooperación y la solidaridad entre humanos y animales; no hay superioridad de unos para con los otros, sino respeto y cortesía.

"Juan desmontó junto al Yurro, sacó a Tía Gallina de su canasta y juntos se comieron un gallito de frijoles y un poco de aguadulce. Después Gallinita golpeó con su pico de oro la Piedra gris. Como por encanto apareció Colipato Azul, la Reina de las Mariposas. Colipato y Tía Gallina se saludaron con mucho cariño, enseguida Pico de Oro le preguntó a Juan Valiente y le dio a su amiga el recado que le mandaba su compadre Tío Conejo. Colipato contesto:

-Tendré mucho gusto en servirte amigo Juan, ¿qué se te ofrecía?" (Ferreto, A., 1982:pág. 57).

A diferencia de novelas como Doña Bárbara y La Vorágine y de cuentos como los de Horacio Quiroga (todos ellos pertenecientes a la literatura latinoamericana del siglo XIX) donde la naturaleza es devoradora de hombres, en estos cuentos y novelas infantiles la naturaleza, como habitat humano, complementa y permite la existencia del hombre y vibra con él en cada instante cósmico.

En síntesis, como ya se ha expuesto, los objetivos humanistas y humanos de la escritora, 
además de su preocupación didáctica, la llevan a presentar en la mayoría de sus producciones para niños un mundo idealizado, armónico y de bien común, en el que el hombre logra su equilibrio con la naturaleza.

\section{El cuento: un espacio de placer y reflexión}

En la génesis del texto "Las palabras perdidas" es posible encontrar la concepción de cuento infantil de Adela Ferreto. Esta reafirma lo expuesto hasta el momento. Desde un principio de la lectura parece sospechosa la reiteración en repetidas ocasiones del término cuento, con el cual se califica tanto a personajes como a objetos. En la narración aparecen las siguientes expresiones: la abuela de los cuentos, la niña de los cuentos, Juan de los cuentos, la choza de los cuentos y casitas de cuento.

En esta narración, un grupo de nif́os, guiados, por Asela, la niña de los cuentos, y un duende también personaje de este mundo mágico, escapan de un mundo altamente tecnificado, deshumanizante y materialista, hacia un pueblo del otro lado, al "revés de este", donde hay felicidad y la naturaleza es aún virgen: un mundo de paz y amor donde los valores de confianza, lealtad, generosidad y amistad se mantienen.

En su urgente necesidad de rescatar valores positivos y tradiciones, Adela Ferreto recurre al cuento infantil y ve en este género literario el terreno productivo que le ayudará a lograr su meta. A través de él podrá comunicar al lector virtual su mensaje, inculcándole valores nobles, de acuerdo con su época y su proyecto ideológico. Todo esto muestra la función humanizante que para ella cumple el cuento infantil.

Los niños al final deciden vivir para siempre en el mundo de los cuentos, en el mundo de la ficción, donde siempre es primavera, en donde es posible lograr el estilo de vida que la autora prefiere para el mundo ¿será acaso la literatura el único espacio donde se puedan concretar los proyectos de Adela Ferreto?

\section{Que los niños hablen a los niños}

Adela Ferreto dirige sus producciones principalmente al niño. Desde un principio sus escritos responden a un proyecto de vida, que se inicia con la maestra y continúa hasta sus últimos días con la maestra-escritora:

"La estima de lo nuestro, la salvaguarda de nuestro acervo cultural, de nuestros valores me ha movido siempre. $Y$ eso me llevó a escribir para niños, pues es en ellos en donde hay que sembrar el amor a lo bello, lo bueno, a nuestra tierra y a otras tierras, al mundo en que vivimos a la justicia y la paz, el entendimiento entre los hombres y los pueblos." (Ferreto, A. Sin fecha. "La novela y los viajes de Chico Paquito y sus duendes").

¿Y por qué al niño y no al adulto? Adela cree en el niño y lo idealiza. Concibe el alma del niño como una alma pura, cristalina e incontaminada, en la que se pueden plantar las bases de un mundo mejor, más libre, con menos diferencias, limpio, fraternal; en fin, el mundo infantil es para ella el espacio en el que la literatura podría contribuir a la transformación de la sociedad.

Pero ese niño no puede transformar la sociedad sinó se le ha enseñado a quererla y a valorarla. Alguien debe hacer esto ¿quién? o ¿quiénes? Adela hábilmente escoge a los seres mágicos, de los que ya se ha hecho mención, y a los mismos niños para que lo motiven en la construcción de un mundo más positivo.

Los personajes en la mayoría de los cuentos y novelas son niños. En ellos se encuentran presentes la ingenuidad, la imaginación y la curiosidad. También su miedo ante lo desconocido y su jocosidad. No son niños perfectos, sino niños como gran parte de los infantes, deseosos de amor, magia y aventuras. Con respecto a esta valoración del mundo infantil, Gladys López (1987:22) señala:

"Estos laberintos de fantasías y disquisiciones mágicas descubren por un lado la capacidad de los niños de suponer a la existencia primaria (real) una segunda existencia (imaginaria) y por otro lado establecer relaciones lúdicas con el mundo.

En Tolo, el Gigante Viento Norte, Nisquito y Pedrín, aparte de su vida familiar y escolar, comparten un espacio mágico. Nisquito tiene como amigo imaginario a un cíclope y Pedrín conoce a los gnomos. Son ellos los que le cuentan sobre su futura hermanita. Situaciones comunes en el mundo de los niffos, se describen con detenimiento en el libro: el hermano mayor con deseos de superioridad, la vergüenza ante la burla de los amigos, las ocurrencias que provocan risa, las travesuras de la hermana menor, las fiestas escolares, el miedo a los aparecidos y otras más. 
"Pedrín, ¿porqué pusiste aquí este cabo de lápiz? -Lo sembré, mamá, a ver si nace, si echa flores

-Ay, hijito, ¡qué ocurrencia! ¿sabes?

es en tu cabecita en donde va el lápiz dará flores

- ¿De veras, mamá?

-Así lo espero

Pedrín salió al jardín muerto de risa:

- Voy a echar flores por la cabeza! ¡qué gozada! (Ferreto, A. 1984c: pág. 16).

La comprensión y el conocimiento del niño que tiene la escritora, hace posible que los personajes infantiles de sus cuentos cautiven al lector niño y lo hagan partícipe de sus aventuras. Cuando Pedrín y Nisquito se deciden a ir en busca de Tolo, el Gigante Viento Norte y para ello se escapan de su hogar y suben hasta la cumbre del cerro, en un primer momento no aparece la censura ante el hecho. El narrador construye un mundo de magia y misterio que muestra la travesura y la transgresión como fascinantes. Pero luego, al finalizar la novela, son los mismos los que exponen las consecuencias que les trajo su aventura.

"- ¿Qué estarán haciendo en casa?, murmuró Pedrín lloroso. Quisiera estar con Runia, con mamá y papá, sollozó.

-Yo también, musitó Nisquito quisiera estar con mis papás, hasta con mi hermano Tolo. ¡Me hace mucha falta mi hermanito!... Pero no vamos a volvernos sin hallar al Gigante... Quisiera verlos a todos... a la abuela, suspiró.

- Mi mamita! ... Debe de estar asustadísimo, aunque es muy fuerte, dice mamá." (Ferreto, A. 1984c: pág. 94).

Miedo, hambre, cansancio y por último una pulmonía que casi acaba con la vida de Nisquito, fueron los resultados negativos de la exploración. Sin embargo, estos contratiempos son recompensados por el disfrute de momentos fascinantes que quedarán como un recuerdo imperecedero.

Con el personaje Chico Paquito se da preferencia a la relación niño-patria. Primero la abuela lo instruye en el mundo de la magia, le cuenta sobre su origen y la multiplicidad de seres mágicos que existen; además le explica la relación de ellos con la naturaleza. Luego se presenta la amistad con Tin Trilín, quien siempre lo visita por las noches. Lo que el niño no aprende con la maestra, el duendecillo se lo enseña en sus distintos viajes. Chico Paquito es un niño bastante distraído y hasta desobediente en muchos casos. El duende le presenta a otros personajes del mundo maravilloso, para que le ayuden en sus enseñanzas, como por ejemplo las hadas del bosque y los retrolines. Las hadas del bosque le muestran los destrozos que han causado los hombres en sus dominios; los retrolines, que son los que cuidan los santuarios históricos, lo educan en la comprensión de la historia de su país y en la valoración de las tradiciones patrias.

Los viajes de Chico Paquito son a través de su imaginación, mediante el ensueño. En uno de estos viajes se escucha la voz del Hada de los Altos Robles, la antigua Reina del Bosque:

"Hermanos, genios del bosque, de los montes y de las aguas, callad! Hemos llorado mucho, hemos tratado de conmover el corazón de los hombres... "-¡Todo ha sido inútil! No lloremos más, no más lágrimas!

Cumplimos nuestra misión, fuimos vida y alegría. ¡Hierbas, insectos, pájaros, flores, frutos, simientes, árboles y bestias formaron nuestro reino maravilloso, ahora casi desapareció!... Ya llorarán sus destructores, los hombres, ya llorarán!...(Ferreto, A., 1983:pág. 18).

Adela Ferreto considera que es injusto que las generaciones futuras deban pagar por estos errores que cometieron los hombres del siglo XIX y cometen los del siglo XX, y por eso lucha por heredarles un mundo más justo y menos contaminado.

Que los niños hablen a los niños, que su magia los cautive, porque su mundo lleno de secretos inviolados, es para la escritora, más transparente y sincero que el del adulto. Para ella, él es capaz de sensibilizarse ante la injusticia y de amar. Pero teme no conseguir su propósito, no encontrar el estilo adecuado para llegar a él:

"Ojalá haya encontrado para decírselos, el lenguaje clave: ¡algunas de las mágicas palabras que ellos entienden y que saben llegar a sus almas y ganarlas! ¿Qué más podría querer? (Ferreto, A. 1984b).

\section{Las palabras mágicas}

¿Cuáles son las palabras mágicas?, ¿dónde surgen? Los niños con sus juegos de palabras empiezan a descubrir la magia del lenguaje. Al principio sólo el ritmo es importante, la musicalidad, luego la posibilidad de jugar con ellas, de crear dobles sentidos. Hay casos en que los niños hasta son capaces de inventar una jerga propia para comunicarse entre ellos y conservar su intimidad fuera del alcance del adulto.

"Las palabras sin sentido, como "larán, larán, larito" imperan mucho en la poesía popular, es la poesía rítmica nada más. Son solamente sílabas sonoras, que tienen mucho que ver, pienso yo, con el niño que todavía no habla, para quien las palabras 
no significan nada"(Ferreto, A. en Sáenz, C. Sin fecha. Las palabras del poeta: pág. 34).

Las rondas infantiles de las que Adela Ferreto se apropia durante la infancia, son en su mayoría variaciones de las traídas por los españoles a Costa Rica: La Pájara Pinta, San Serenín del Monte, que aquí se transforma en San Selerín, Matarile, rilerón y otras. Su mundo de niña se desenvuelve entre estos juegos infantiles. Es a este folclore al que dirige sus ojos como escritora y con él empieza a experimentar la magia del lenguaje.

El lenguaje literario sigue una lógica distinta. Julia Kristeva, lo denomina como un espacio para-gramático, un lugar donde se violan las leyes de la lógica tradicional, en el que coexiste el binomio ficción - realidad.

Para Adela Ferreto, el mundo de los cuentos y los poemas para niños está regido por la lógica de lo maravilloso, proviene del alma que no se ha corrompido por el raciocinio, "en lo que la piedra alienta lo mismo que el torrente"... en la que las identidades se transtruecan y transmutan unas en otras y las cosas se confunden $e$ intercambian" (Ferreto, A. 1984a: pág. 7).

En los cuentos de Adela Ferreto el lenguaje está inserto en este paragramatismo; con él, ella pretende cautivar al niño, que necesita de fantasía, y desea jugar con las palabras; para quien, según ella, un poema racional sería una herejía. Como ejemplo, en Las aventuras de Tío Conejo y Juan Valiente el nombre mismo de los personajes sumerge al lector en el universo poético: Ojos de Rubi, Cola Esponjada, Pico de Oro, Cascos de Acero, Campanilla, Alas de Encaje, Coposita.

Las palabras mágicas construyen un mundo también mágico, donde cosas, animales y plantas tienen vida, una "segunda" realidad que a pesar de su distanciamiento del mundo racional es comprendida por el niño, y que por su referencialidad con el momento histórico en que vive lo encamina a la adquisición de valores patrios y familiares y a reaccionar en forma crítica ante los problemas sociales como el desamor para con la naturaleza. La magia es entonces el camino encantado que le permite llegar, entre el placer y el misterio, al corazón del niño.

\section{La abuela se transforma en leyenda}

En las producciones de Adela Ferreto predominan los niffos, pero también aparece la abuela como un personaje muy importante, pues representa la unión del pasado con el presente. A través de ella los niños se inician en la aprehensión de lo maravilloso. En Tolo, el Gigante Viento Norte, la abuela es una maestra pensionada que les transmite sus conocimientos mediante cuentos. Entre su mundo y el de los niños hay mucho en común; comparten en la cotidianidad familiar: juegos, recuerdos y ternura. Ella además, representa la sabiduría y la experiencia para los pequeños.

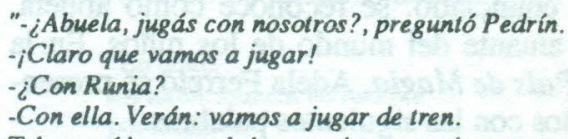

El tren era una larga escalera puesta en el suelo, en el zacate del jardín; cada peldaño, un asiento que ocupó algún pasajero" (Ferreto, A, 1984c: pág. 27).

En Las palabras perdidas, los niños que buscan conocer su significado, consiguen su objeto con la ayuda de la abuela. En un mundo donde lealtad, amistad y amor son considerados como arcaísmos fuera de uso, sólo la Abuela de los Cuentos guarda el significado de las cosas viejas y puede ayudarlos en su misión. Sus padres que no eran padres biológicos, porque ellos habían nacido en una probeta, viven en un mundo materializado donde solo interesan los negocios y los armamentos bélicos.

La abuela rescatada en todas las narraciones, obedece a una misma descripción. Es una leyenda de bondad y ternura.

"La Abuela, sentada en su poltrona, con los anteojos medio caídos sobre la nariz, los ojillos alegres, las mejillas sonrosadas y una sonrisa tiema y acogedora en los labios, les tendió los brazos.

-¿Qué tibia!, iqué suave eres! Abuela, tienes una suavidad que se mete en el corazón, dijo Malena, una de las niñas más pequeñas del grupo, acurrucándose en su regazo." (Ferreto, A. 1986b: pág. 21).

La abuela es para los niños como el vientre del que les privó la ciencia; por eso la describen como tibia, suave y se acurrucan en ella. Ella es el origen, un personaje simbólico, donde no cabe ningún valor negativo. Les enseña el significado de las palabras perdidas a través de hermosas narraciones de clásicos universales, entre las que destacan: "El cuento de navidad", "La Sirenita", "El príncipe feliz", etc. 
"Tú eres nuestra Abuela y nos has enseñado el amor y todas las palabras perdidas, las bellas palabras que no conocíamos. Eres lo mejor que tenemos. ¡Déjanos contigo! (Ferreto, A. 1986b: pág. 23).

Cabe destacar aquí que Adela a sus setenta años, momento en que empieza a escribir y a publicar sus textos de literatura infantil, manifiesta cuáles han sido sus preocupaciones por los niños, su amor por la literatura y su propósito de enseñar a través de ella. Inclusive, desdoblada en sujeto del enunciado, se reconoce como abuela, maestra y amante del mundo de los niños. En la antología País de Magia, Adela Ferreto se presenta a los niños con las siguientes palabras:

\section{"¿Qué quién soy yo?}

¿Que por qué escribí estos cuentos?

Se lo voy a decir:

Soy una abuela, podría ser bisabuela...jUy, qué viejita!

Tengo nietos y les cuento cuentos. Desde que era una chiquilla, allá en Heredia- porque soy herediana aunque hace tiempo vivo en San José -desde que era chiquilla, les decía, me gustaba contar cuentos, y que me contaran cuentos. Me hice maestra, y les contaba cuentos a mis niñas; también se los conté a mis hijos...Porque me casé con el Abuelo Cuenta Cuentos, ffigúrense!, cuando no era abuelo por supuesto, pero sí contaba cuentos en una revista que hicimos para los niños y que se llamaba Triquitraque.

Así es que, gustándome tanto los cuentos y casada con Cuenta Cuentos ¿qué tiene de raro que ahora, cuando podría ser la bisabuela de ustedes, me ponga a escribir cuentos, no les parece?

Ojalá les gusten y se entretengan con los cuentos de esta abuela bisabuela, que quisiera vivir con ustedes en un mundo de niños, de cuentos, de hadas y de duendes y de gigantes buenos.

Métanse por un cuento y sálganse por otro y licgo, mr dicen si quieren que les cuente otro" (Ferreto, A. y otros, 1982: pág. 37).

A esa edad y en la vida real, se iba acercando a la abuela legendaria de sus cuentos; con ropa oscura, un moño y anteojos, inspiraba respeto y evocaba el recuerdo y la tradición.

\section{Conclusión: Edificando un mundo entre el temor y la nostalgia}

Adela Ferreto, como sujeto consciente de su propia historicidad, tiene una visión clara de las transformaciones ocurridas en el mundo y especialmente en nuestro país durante el siglo XX. Su existencia (1904-1987) le permite apreciar cómo van surgiendo las ciudades y cómo los ríos de aguas cristalinas se van tornando turbios y hasta desaparecen. Ella vive en una era de transición para la humanidad, era de guerras mundiales y de un avance desmedido de la tecnología. Su conocimiento del mundo la lleva a escudriñar en el pasado y a rescatar todo lo positivo que éste encierra, para proyectarlo al presente y al futuro; sin embargo, su profundo conocimiento del hombre también la hace temer por el mundo venidero.

Entre la nostalgia de un pasado y el temor a un futuro incierto, la escritora va forjando el ideal de nuestra sociedad. La nostalgia se presenta principalmente en sus Crónicas de un tiempo, un texto en el que se muestra la vida de la sociedad herediana del primer tercio de este siglo. En el proceso de selección del material social que forma parte de su trabajo, ella escoge lo positivo, mostrando un ideal de hombre, de vida familiar y de sociedad. Esto puede observarse en el caso concreto de los médicos:

"Pero nuestros viejos médicos, sencillos y familiares, eran algo así como una mano de la Providencia: visitaban enfermos a cualquier hora que se los llamara y si la gente no podía pagar, hasta le regalaban la medicina. Eran baratos y generosos; inspiraban fe y confianza a las gentes" (Ferreto, A. 1978: pág. 15).

Adela reconstruye el pasado con el fin de comparar el sistema de vida de los inicios del siglo XX con el actual. Por ello la narración tiene un matiz de dolor: "si todo fuera hoy como fue antes sería mejor". Los niños tendrían más espacio para jugar, habría más solidaridad, estaríamos más enraizados con lo nuestro: costumbres, tradiciones, valores patrios:

"Ahora, el llamado progreso, con sus carros y bloques de cemento, ha barrido las rondas, los cantos infantiles, los juegos. Ha robado el espacio y, al robarlo ha despojado a los niños que viven en jaulas, como pajarillos presos, privados de su derecho al juego, al movimiento, a la actividad libre" (Ferreto, A. 1978: págs. 123-124).

El deseo de eternizar los tiempos idos y de volver a vivir el pasado de su infancia son dos importantes razones que llevan a la génesis de este libro:

"Se me ocurrió escribir algo de la vida de aquella Costa Rica de mi infancia. El mundo ha cambiado tanto que es irreconocible y pensé que era importante que quedara un testimonio de lo que una vio y vivió" (Ferreto, A. citada por Muñoz, F. 1983: pág. 16).

En Los viajes y aventuras de Chico $\mathrm{Pa}$ quito y sus duendes lo pretérito es un espacio mágico al que se llega a través del ensueño. Tanto este libro como las Crónicas de un tiempo son muestra de la urgente necesidad de la escritora 
por hacer presente el pasado con el fin de aleccionar al hombre.

Este juego temporal se complementa con la alusión al futuro. A Adela le preocupa la herencia que le está dejando la humanidad a las generaciones venideras. En su poema El rostro del futuro, el yo lírico expresa su angustia ante el desconocimiento de lo que está por venir, su temor ante la deshumanización del hombre. Deshumanización que lo acerca cada vez más a la insensibilidad de la máquina:

\author{
"El orden de las máquinas acecha. \\ ¡Un mundo nuevo! \\ ¿Es desde allí que arrancará el futuro? \\ ¿Qué seremos? \\ ¿Robots...monstruos de hierro... \\ inteligencias puras? \\ ¡Razón...Razón y \\ sinrazón perfectas! (Ferreto, A. 1986a: pág. 6).
}

El yo lírico se presenta como una síntesis de la humanidad. Todo lo pasado está en él desde los orígenes, no solo del género humano sino de la creación misma del universo. Entre él y el futuro surge un abismo de duda y de incertidumbre:

\footnotetext{
"El pasado remoto me acompaña, está en mi sangre y corre por mis venas. El pasado remoto....¿El más remoto?

Mundos en gestación...y, desde siempre, lucha de las especies,

lucha certera y ciega...¡Evolución!

Vida proteica, innúmera al final

¡el hombre! (Ferreto, A. 1986a: pág. 2).
}

En el poema el yo lírico trata temas de la historia universal y hace ver que la paz es precaria y abundan la miseria y la violencia. Ese mundo es un océano tenebroso donde la voz del maestro se pierde.

Pero al mismo tiempo que el yo lírico es el pasado, también es el futuro. Sus acciones van a repercutir en el tiempo próximo; hay una ausencia presente. Al fin y al cabo la historia con su división temporal (pasado- presente y futuro) es la historia de la humanidad:

\footnotetext{
"¿Esas mil y mil sendas del pasado, esos mil y mil rostros, están en mí, en mi came y en mi sangre!

Son yo, viniendo por antiguas rutas, son los que veo y los que no conozco... y en nosotros están las formas del futuro" (Ferreto, A. 1986a: págs. 3-4).
}

En el poema se presenta un lamento ante la forma en que los avances tecnológicos han esclavizado al hombre, conviertiéndolo en un consumista de los más variados artefactos. Compra para desechar y trabaja para adquirir las últimas novedades del mercado. Estas situaciones no le permiten un acercamiento real y afectuoso a la familia y a la comunidad.

La angustia del yo lírico se acrecienta cuando compara el mundo de los que todo lo poseen con el mundo de los miserables:

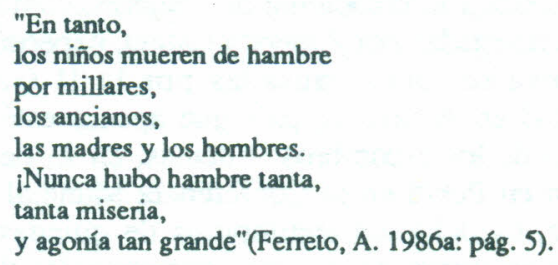

El rostro del futuro se desvanece ante el yo lírico, que sólo vislumbra abismos, egoísmo, valores humanistas silenciados y el horror de la guerra. Una guerra instantánea causada por armas nucleares, maldito fruto de la inteligencia humana. En "El huevo del Ave Rock" también se hace alusión a la guerra nuclear; el texto bélico es común en ambas producciones, en las que predomina una visión pesimista del mundo. En el cuento "El huevo del Ave Rock", el huevo, que significa la bomba atómica lanzada por un avión de guerra, cae sobre un atolón madrepórico, una isla virgen donde todos los animales vivían en armonía y produce terribles consecuencias:

"Lo malo, es que no se sabe si el Ave Rock ha muerto o está viva, y de estar viva, nadie sabe tampoco, en qué momento, al pasar sobre una isla feliz, decide poner uno de sus fatídicos y mortales huevos. ¡Nadie puede saberlo!

Por eso los pájaros viven con el miedo en el corazón, por eso sus cantos tienen un dejo de tristeza"(Ferreto, A.1986b: pág. 61).

El poema "El rostro del futuro", inédito, y "El huevo del Ave Rock" son las únicas producciones de Adela en que se aprecia una visión pesimista del mundo; en todas sus otras producciones literarias existe un predominio de lo positivo. Sin embargo, estudiar estos trabajos con el sentido, permiten develar el alma sensible de la escritora, un alma en la que se debaten fuerzas opuestas, como el temor y la esperanza. Por eso callar esta faceta sería presentar una visión parcial y fragmentada: 
"No es que no quiera ver el futuro, pero le tengo miedo. Lo veo muy oscuro. No sé por qué el hombre está œerrando sus caminos y no sé hacia dónde se dirige. Quizá eso me hace que vuelva la mirada hacia la literatura infantil, hacia las grandes leyendas y tradiciones de nuestro país y sienta el gran deseo de dárselas a los niños, porque están cargadas de un espíritu positivo, de fe, de esperanza y también de caridad. Hacia el futuro lo que veo es solamente el espectro de la guerra"(Muñoz, F. 1983: pág. 16).

El contexto histórico en el que ella se desenvuelve explica su horror ante la guerra. Adela Ferreto cuando colabora con la Federación Democrática Internacional de Mujeres, como una de las delegadas por América Latina, experimenta las devastaciones causadas por la II Guerra Mundial en Alemania, país que apenas está surgiendo de los escombros. Además, en su participación en Pekín en la Conferencia Mundial para la Paz, escucha los testimonios de quienes han vivido en forma directa las consecuencias de las guerras.

Pero ante este temor al espectro de la guerra, ella recurre a la literatura e intenta construir a través de ella un mundo mejor. Entre la nostalgia y el temor surge la esperanza. ¿Con qué fin dedica ella los últimos diez años de su vida a escribir para niños? ¿Con qué razón rescata el espíritu positivo del pasado: tradiciones, leyendas, valores? Para construir con ellos una sociedad más positiva:

"Adela, a pesar de su conciencia histórica, de su conocimiento de la dura realidad, es el poeta de lo positivo, porque tiene fe en el hombre"(Pérez, M. 1985: pág. 112).

Adela concibe el acto de escritura como un acto de amor pues para escribir hay que amar, como un hecho altruista y solidario. Por ello intenta en sus producciones cumplir con la función de guía espiritual que ella misma le exige a todo poeta. En ella, como sujeto colectivo, se concretan las metas de muchos hombres.

\section{Bibliografia}

\section{A. Textos teóricos}

Ferreto, A. 1985. Las fuentes de la literatura infantil y el mundo mágico. San José, Costa Rica: Ministerio de Cultura, Juventud y Deportes.
Kristeva, J. 1974. El texto de la novela. Trad. Jordi Llovet. Barcelona: Lumen.

\section{B. Sobre Adela Ferreto}

Ferreto, A. 1984b. "A propósito de mi novela Los viajes de Chico Paquito". En: La Nación. San José, Costa Rica (2 de agosto).

López, G. 1987. "Valoración del mundo infantil en la obra de Adela Ferreto". En: La República. San José, Costa Rica (11 de julio).

Marín, M. 1987. "Polifacética inolvidable". En: Contrapunto. San José, Costa Rica (1 de junio).

Muñoz, F. 1983. "La hora del cuento". En: Contrapunto. San José, Costa Rica (16 de abril).

Pérez, M. 1984. "La literatura infantil en Costa Rica(1900-1984) y el mundo mágico de Adela Ferreto". En: Káñina. IX (1): 101118.

Pérez, M. 1985. "La polifacética Adela". En: Káñina. IX (2): 57-60.

Pérez, M. 1991. "Apuntes para una reflexión: Nuevas tendencias de la literatura para niños y jóvenes". Revista Comunicación. 5(2):15-23.

Sáenz, C. (Sin fecha) Las palabras del poeta. (Guión de la película del mismo nombre).

\section{Textos de Adela Ferreto}

Ferreto, A.1978. Crónicas de un tiempo. San José, Costa Rica, Editorial Costa Rica.

Ferreto, A, 1982. Las aventuras de Tio Conejo y Juan Valiente. San José, Costa Rica: Editorial Costa Rica.

Ferreto, A, 1983. Novela de los viajes y aventuras de Chico Paquito y sus duendes. San José, Costa Rica: Editorial Costa Rica. 
Ferreto, A. 1984a. Las fuentes de la literatura infantil y el mundo mágico. San José, Costa Rica: Ministerio de Cultura, Juventud y Deportes, Instituto del Libro, 1984.

Ferreto, A. 1984c. Tolo, el gigante viento norte. San José, Costa Rica: Editorial Costa Rica.

Ferreto, A. 1986a. "El rostro del futuro". Inédito. 1986.

Ferreto, A. 1986b. Las palabras perdidas y otros cuentos. San José, Costa Rica: EUNED.
Ferreto, A. 1991. Cuentos del Niño Dios y de la tradición cristiana. San José, Costa Rica: Editorial Costa Rica.

Ferreto, A. (Sin fecha). "El oficio del escritor". Inédito.

Ferreto, A. (Sin fecha). "La novela y los viajes de Chico Paquito y sus duendes". En: $L a$ República. San José, Costa Rica.

Ferreto, A. y otros. 1982. Pais de magia. San José, Costa Rica: Editorial Costa Rica. 
